\title{
Developing Effective Learning Environments in Physical Education
}

\author{
By Jean-François Desbiens ${ }^{*}$ \\ Carlo Spallanzani ${ }^{\dagger}$ \\ Martin Roy \\ Sylvain Turcotte \\ Sèverine Lanoue \\ Jean-Sébastien Tourigny
}

Objectives: This study aimed to explore Health and Physical Education (HPE) learning environment, and to examine students' perceptions of the interaction behaviours of trainee teachers. Methods: Twenty-five trainee teachers at the completion of their fourth year of professional training and 565 high school students participated in this study. Data collection was carried out using three observation systems and one high-inference questionnaire on trainee teachers' behaviour perception. Descriptive and multivariate nonparametric statistics were used to analyse the data. Results: Trainee teachers provided encouragement and were perceived by the students as cooperative and supportive. However, appropriate motor engagement was low (mean $<15 \%$ ) while waiting time and disruption levels were high (mean > 30\%). Disruptive behaviour frequency was closely related to inadequate class and group organisation, low to very low levels of perceived support and control, and trainee teacher "Ignore" behaviour. On the other hand, adequate motor engagement related to high incidence of appropriate verbal communication, high levels of class organisation, appropriate task difficulty and high to very high levels of perceived support and control. Even if students favourably perceived their trainee teachers' interaction behaviours, the learning climate that prevailed in trainee teachers' HPE classes was not likely to allow the attainment of high-order learning objectives. In addition, trainee teachers seemed to experience the dilemma of how to act supportively without falling into permissive pedagogy. Conclusion: These results raise a number of questions in regards to HPE professional training efficacy.

\section{Introduction}

\footnotetext{
*University of Sherbrooke, Canada.

${ }^{\dagger}$ University of Sherbrooke, Canada.

University of Sherbrooke, Canada.

${ }^{+}$University of Sherbrooke, Canada.

University of Sherbrooke, Canada.

University of Sherbrooke, Canada
} 
In Quebec (Canada), Health and Physical Education (HPE) is a compulsory subject that contributes to positive or negative academic experience for all Quebec high school students (MELS, 2007). The climate of HPE classes, when favourable, can greatly influence student's learning without guaranteeing it (Siedentop, 1994). Teachers' verbal and non-verbal behaviours, along with their attitudes, are the climate's strongest and most representative factors (Brunelle et al.1983). Teacher's enthusiasm, for example, has long been known to play a critical role vis-à-vis the students' attitudes and motivation in school (Brophy \& Good, 1974; Siedentop, 1994; Dumas, 2009). Research findings on HPE climate demonstrated that teachers are not very enthusiastic or warm during classes, and that emotional climate is neither positive nor coercive, but rather neutral (Brunelle et al.,1983; Siedentop, 1994; Ward, 1982).

The learning environment (LE) in this study forms part of the teaching efficacy paradigm that according to Martel et al. (1991) is "the working atmosphere that prevails during a teaching session and that is manifested by the degree of involvement of participants in achieving required tasks". This conception of LE puts the learner in the epicentre of the learning experience with the learner expressing enthusiasm, care, deviance, passivity or inconsistency (see Diagram 1). Martel et al. (1991) argued in their model that student involvement is influenced by context and activity variables as well as behaviours adopted by trainee teachers and students during a session and that students' involvement can be examined from various angles. For the purposes of this paper, only two main angles were analysed: motor engagement and students' deviance episodes. Previous research that has analysed academic learning time has shown that less than $75 \%$ of session time is devoted to cognitive and motor learning activities and that learners spend more time in organisation than participation in motor learning activities (Brunelle et al., 1996). Several factors such as the number of students in a class, their attention and responsiveness, the equipment available, the subject and the teacher's emotional and mental state, attention and level of experience strongly influence motor engagement time (Griffey \& Housner, 1991; Silverman et al., 1991).

The analysis of students' deviance shows that there is large number of non-compliance behaviours that occur during HPE classes (Turcotte et al., 2008). Amongst observed disruptive behaviours, those likely to disrupt a class short to medium-term are most frequent, followed by those having less influence on the gymnasium's ecology. Observations made by Desbiens et al. (2008) with high school students indicate that classes run by second and fourth year HPE trainee teachers could not create all the characteristics of an environment conducive to learning while the degree of disruption was relatively high ( $\mathrm{M}=0.82$ disruptive behaviours/min). Highly and moderately disruptive behaviours were most frequent ( $48.2 \%$ and $31.0 \%$, respectively) while least disruptive ones occurred less often (20.8\%). Despite the efforts made over the last few years to improve HPE teacher training, we understand that, for trainee teachers (TTs) or for inexperienced teachers, creating an environment conducive to learning remains a major challenge. 
Adding to elements identified above, we believe an analysis of LE should also consider the students' judgments on the quality of their learning environment (Fraser, 2001) because these perceptions influence their behaviours and learning (Ward, 1982). Moreover, research findings by Legault \& Lapointe (1999) suggest that the most effective teachers are both dominant and cooperative i.e. the more dominant the teachers are the better students succeed, while the more cooperative teachers are the better students' school attitudes are. Therefore, the more students perceive their teacher to be dominant and cooperative, the better their commitment should be towards the subject (free translation from French by the authors).

Diagram 1. The Learning Environment. Adapted from Martel et al. (1991)

Student's perceptions of trainee teachers' interaction behaviours, teaching context and learning activities

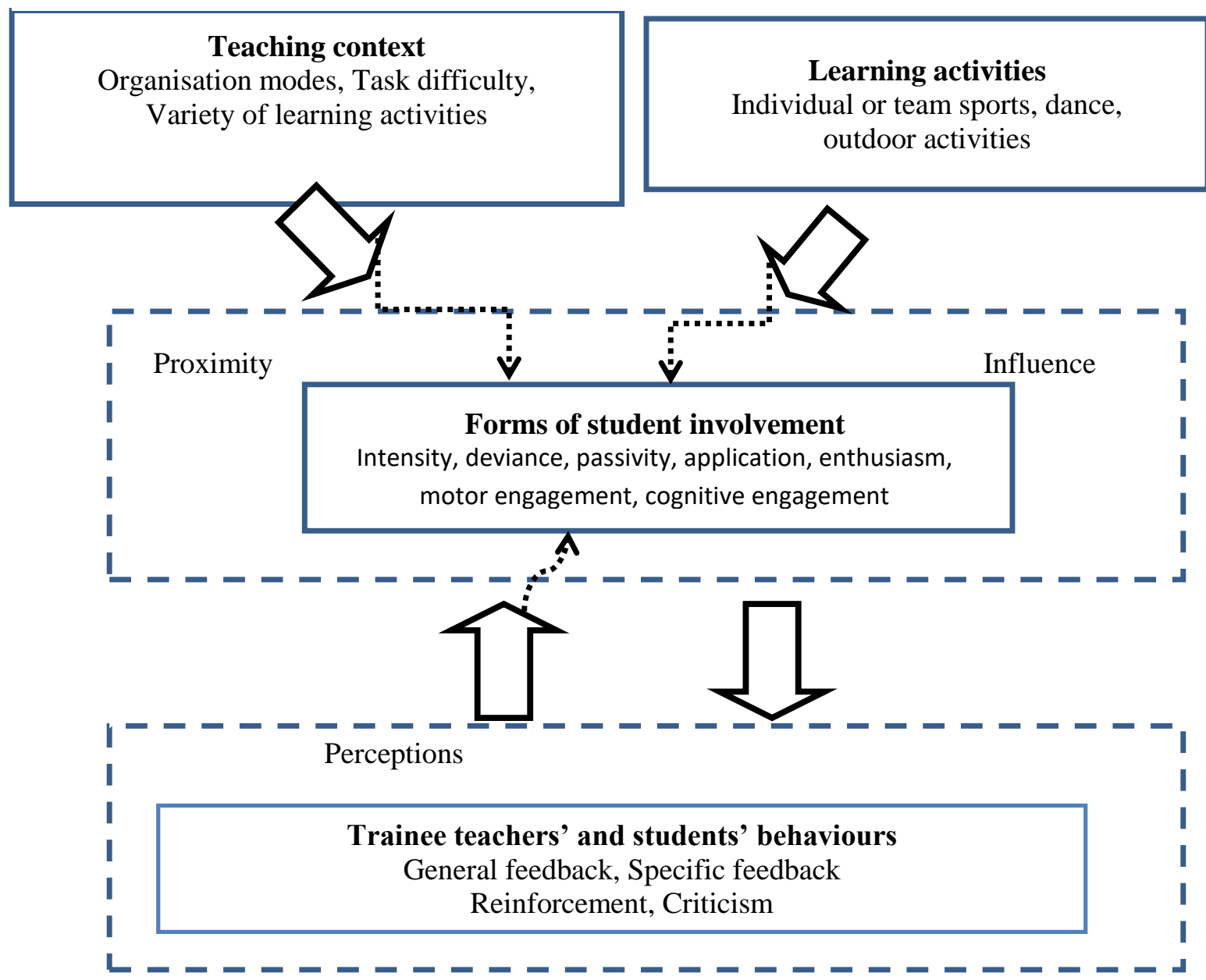

Note. The proposed model integrates the students' perceptions (dotted lines) of the trainee teachers' interaction behaviours and shows the connections between the main dimensions that are thought to be linked to the learning environment. Dotted arrows signify possible distortions due to perceptual process.

Considering what precedes, we believe that taking into account the students' perceptions about trainee teachers interaction behaviours can enrich 
the LE model analysis retained in this study by introducing subjective data and by opening additional opportunities to examine the relationships between low inference behavioural variables and high inference perceptual variables that are closely linked with it. Therefore, the purpose of this study was to analyze LE in high school HPE classes lead by fourth year TTs. The originality of the study lies in that it uses three systematic observational systems used separately in previous studies. These studies have analysed the effectiveness of HPE teaching in Quebec over the last 30 years. The study also uses a questionnaire validated with Quebec populations to produce a comprehensive portrait of student teachers interaction behaviours. More specifically, this article intends to verify the following two hypotheses:

1. LE in high school classes lead by graduating TTs is not conducive to learning;

2. LE created by TTs involvement corresponds with high to very high perceptions of support and control by students. Methods

\section{Participants}

The study included a convenience sample of 25 TTs (8 women and 17 men) teaching HPE in a high school setting. The age range of the students was 12-17 years and included first to fifth high school year students $(n=565)$. All participants were informed of the aims of the study and of the steps taken by researchers to preserve their anonymity and the confidentiality of the raw data.

TTs were engaged in an intensive seven week internship, with full teaching responsibilities, during the final semester of their four year professional training. They were observed only once, between the fifth and seventh week in the context of teaching-learning situations that took place in a gymnasium. TTs and students were involved in different educational contexts that included: combat sport $(\mathrm{n}=1,4.0 \%)$; physical fitness activities $(\mathrm{n}=3$, $12.0 \%)$; technical-artistic activities $(\mathrm{n}=1,4.0 \%)$; cooperative activities $(\mathrm{n}=1$, $4.0 \%)$; cooperation and opposition activities $(\mathrm{n}=17,68.0 \%)$ and dual activities $(\mathrm{n}=2,8.0 \%)$.

\section{Data Collection}

Data collection was conducted using the Academic Learning Time Physical Education (ALT-PE) ${ }^{1}$ systematic observation technique by short intervals (Brunelle et al.1996). For each group, four randomly selected students were observed $\left(n_{\text {total }}=100\right)$. The mean inter-rater $(n=4)$ reliability (Fortin et al.2006) was $93.5 \%$.

LE and disciplinary incidents data was collected using video recordings. A total of 25 sessions, each lasting 75 minutes, were filmed using two cameras and a wireless microphone. These sessions were later analysed for disciplinary

${ }^{1}$ French 3 rd version except for coding motor engagement which is (+: appropriate; - : non appropriate) like in version 2 (Brunelle et al., 1996, p. 33). 
incidents using the Learning Environment Observation System (LEOS) (Martel et al., 1991). The mean inter-rater reliability $(\mathrm{n}=4)$ was $86.5 \%$.

The Disciplinary Incident Observation System (DIOS) was developed by Brunelle et al.(1993). It is based on a strategy of delayed systematic videoscopic observation. In this article, we considered only the degree of intensity of students' disruptive behaviours (grade 1: low intensity - grade 3: high intensity) and the three main types of pedagogy styles (authoritarian, permissive and interactive) in which TTs reactions were classified. The mean inter-rater reliability $(\mathrm{n}=5)$ was $86.3 \%$ for identifying incidents, $88.0 \%$ for coding disruptive behaviours and $93.1 \%$ for coding reactions to disruptive behaviours.

Students' perception about TTs' interaction behaviours was examined using the French version of the Questionnaire for Teacher Interaction (QTI) previously validated by Legault and Lapointe (1999). This forced-choice questionnaire (1: totally disagree to 2: strongly agree), was composed of 32 items and was divided into eight subscales (leadership, benevolence, indulgence, permissiveness, uncertainty, dissatisfaction, punishment and requirement). It was used to extract the "Proximity" construct (opposition cooperation axis) and the "Influence" construct (domination - submission axis) which characterize the interpersonal style of trainee teachers.

\section{Data Analysis}

Data collected on the ALT-PE were analysed using a frequency count by category. Absolute and relative frequencies were calculated. The average per class for the entire sample was also calculated. The estimated average time spent in proportion to each type of situation as well as the time spent on each of the participants' targeted behaviours was calculated using the average number of listed intervals for each reported over the total number of intervals measured. The data collected using the LEOS was analysed using a frequency count of TTs' behaviours of teaching context characteristics, whereas the mean and standard deviation (SD) of the changes in learning situation (LS) scenarios was calculated.

Students' disruptive behaviours and TTs' reactions using the DIOS were calculated using the frequency of occurrence of each of the behaviours. The relative frequency and the mean \pm SD were also calculated. Disruptive behaviours were grouped into a new variable called "Total Behaviour problem" which is the sum of disruptive behaviours for each session observed. Multivariate analysis involved that continuous variables whose distributions did not meet the criteria of statistical normality were broken down into discrete categories. This conversion allowed making the data homogeneous, and exploring variables whose distributions were irregular.

Two multiple correspondence analyses (MCA) (Desbois, 2008; Escofier \& Pagès, 1998) were conducted to map the relationships between the variables. The first MCA examines correspondence between modalities of one TTs' variable ("Teacher gender"), those of two context variables ("Organization 
mode" and "Task difficulty"), those of a programming variable ("Type of activity"), those of four process variables including two related to student behaviour ("Total Behaviour Problem (BP)" and "Motor engagement") and two related to TTs' behaviours ("Impose behaviour", "Ignore behaviour"). The second MCA examines the correspondence between modalities of the same variables presented above in addition to the variables "Influence", and "Proximity", "Verbal expression" and "Wait time". All statistical analyses were performed using SPSS software (Appache software foundation, version 15, 2006) and XLStats software (Addinsoft, 1995-2009).

\section{Results}

The targeted groups spent an average of $34.49 \% \pm 16.11 \%$ of their time on preparatory activities, while $65.51 \%$ of class time was allocated to knowledge development $(\mathrm{M}=6.93 \pm 9.73 \%)$ and motor development $(\mathrm{M}=58.58 \pm$ $32.25 \%$ ). The average proportion of time spent on appropriate motor engagement amounted to $14.3 \%$ of total time while the proportion of average waiting time corresponded to $32.1 \%$ of total time. The targeted students were engaged in appropriate motor activity less than $20 \%$ of the time while they were waiting for nearly one third of the time. The courses were also characterised by a relatively high degree of disturbance. Indeed, it was possible to count an average of 0.71 behavioural problems (BP) / minute. More than half $(51.0 \%)$ of BP were very disruptive.

TTs' disciplinary actions were mostly permissive (58.54\%) ("Ignore behaviour" alone accounts for 57.86\%) and authoritarian (36.61\%) ("Impose behaviour" alone accounts for $35.32 \%)$ rather than interactive (4.85\%). In terms of $\mathrm{LE}$ regulation, general positive feedback $(\mathrm{M}=20.84 \pm 11.44)$ and specific neutral feedback $(\mathrm{M}=18.88 \pm 10.79)$ were also behaviours with a relatively higher average frequency of use. The students' perception of TTs' interaction behaviours was quite favourable since the average reported for the "Proximity" variable was $14.69 \pm 5.81$, whereas the average for the "Influence" variable was more than three times lower $(M=3.82 \pm 2.54)$.

Figure 1 shows that the "Activity type" (27.2\%), and "Impose behaviour" (20.4\%), "Teacher gender" (18.6\%), and "Motor engagement" (15.7\%) explain $81.90 \%$ of the first dimension's cumulative inertia. The adjusted percentage of inertia of the former is $39.08 \%$, while the second is $23.86 \%$. It appears that a high frequency of episodes of appropriate motor engagement closely corresponds to male TTs and with a low frequency of disruptive behaviours, a high frequency of appropriate task difficulty episodes, and a low frequency of "Ignore a behaviour" and "Impose a behaviour". The modality indicating a high frequency of episodes of appropriate motor engagement is also related to participation in situations of fitness ("Activity type-2"). In contrast, a low frequency of episodes of appropriate motor engagement (-1) corresponds more closely to situations headed by female TTs $(-1)$, low frequency of episodes where the degree of task difficulty is appropriate (-1) and high frequency of 
"Impose a behaviour-2".Moreover, we find that dual, cooperative / artistic and technical activities (Type of Activity 6, 4 and 3) tend to be associated with a high occurrence of "Motor engagement-1" episodes.

Figure 1. Multiple Correspondence Analysis (MCA) illustrating the Relationship between Modalities of the Variables "Motor Engagement", "Activity Type", "Gender", "Total Behaviour Problems", "Impose a Behaviour", "Ignore", "Organization Mode" and "Task Difficulty"

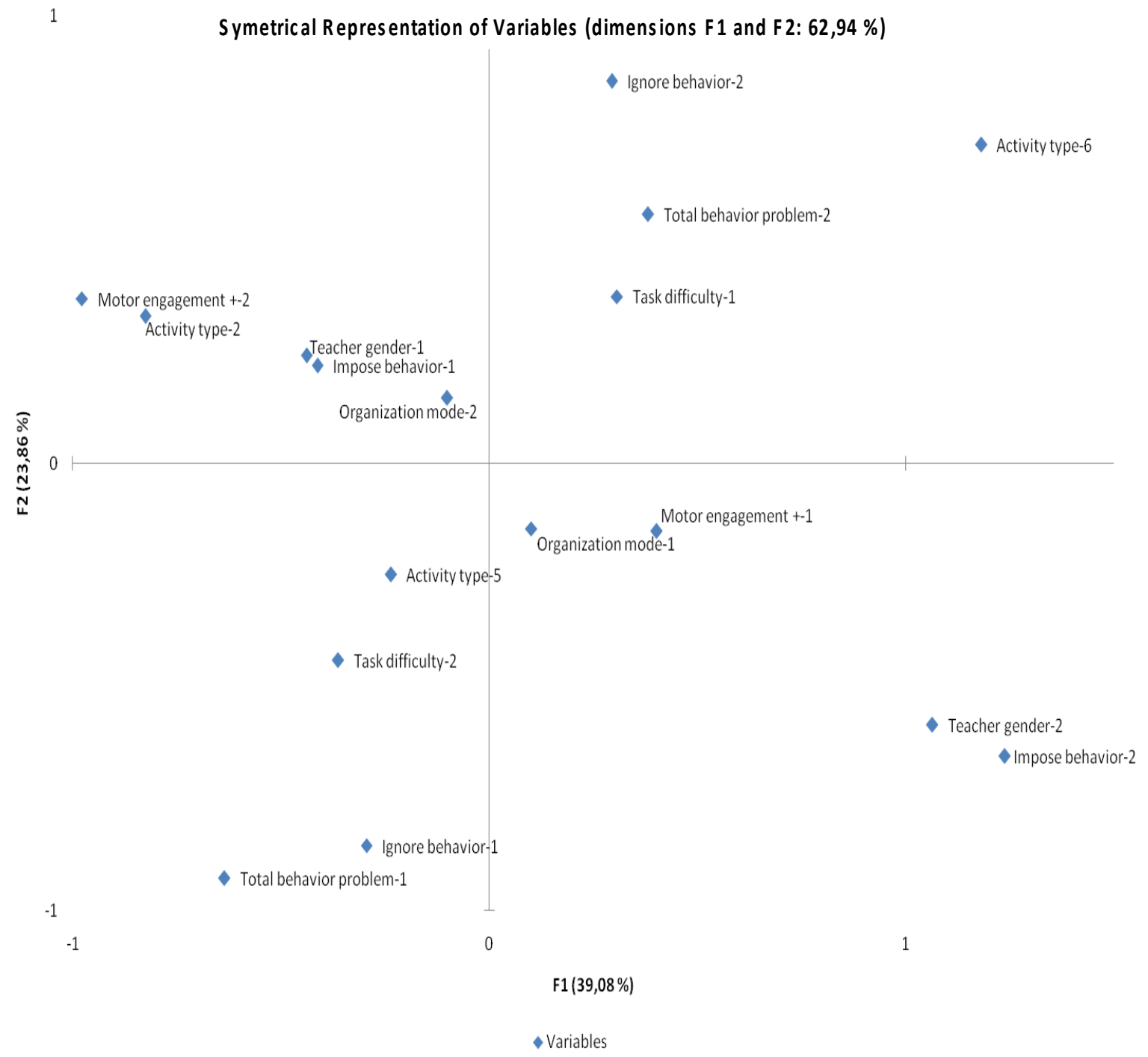


As shown in Figure 1, the orderly conduct of the HPE course is highly defined by the modalities of the variable "Total behaviour problem". A high frequency of disruptive behaviours (-2) corresponds with a low frequency of episodes of efficient organization (-1), a low frequency of episodes of adequate task difficulty (-1) and a high frequency of episodes in which TTs ignore the behaviour (-2) or undesirable situations. In contrast, a low frequency of episodes of disruptive behaviours corresponds to tasks whose level seems better suited to the abilities of students (-2), to high appropriate motor engagement (-2), to highly structured activities and to male student teachers.

Figure 2 shows the results of a second MCA. It indicates that the contributions of "Positive specific feedback" (18.6\%), "Specific neutral feedback" (18.1\%) and "Proximity" (11.4\%) explain $48.10 \%$ of the first dimension's cumulative inertia. The adjusted percentage of inertia of the first dimension is $47.93 \%$ whereas the second dimension's is $22.56 \%$. The modality "Very high"(4) of the variable "Proximity" is associated with a high frequency of "Motor engagement-2", with "Specific neutral feedback-2", "Positive neutral feedback-2" and "Task difficulty-2" episodes. Remarkably, results show that higher degree of Proximity is not inconsistent with a similar degree of Influence since these modalities coexist in the same quadrant near adequate motor engagement. The presence of "Ignore behaviour-2" appears difficult to explain here because it seems hard to reconcile with the idea of high or very high influence. The perception of low and high proximity ("Proximity-2, 3") is associated with female TTs, but also with "Motor engagement-1", "Specific neutral feedback-1", "Positive specific feedback-1", "Task difficulty-1", and "Ignore behaviour-2". Modalities 1 and 2 of the variable "Organisation mode" oppose each other in Figure 2. Modality 1 attracts the "Proximity" modalities "Low (2)" and "High"(3), the "Influence" modalities "Very low (1)" and "Low"(2) and corresponds to a low degree of waiting time (-1) as well as TTs' behaviours such as "Positive specific feedback-1" and "Neutral specific feedback-1". For its part, "Organisation mode-2" is related closely enough to "Positive specific feedback-2" and "Neutral specific feedback-2", "Wait time-2 as well as "Promity-3,4" and "Influence-4". 
Figure 2. Multiple Correspondence Analysis (MCA) illustrating the Relationship between Modalities of the Variables "Motor Engagement", "Waiting Time", "Gender", "Total Behaviour Problem", "Impose a Behaviour", "Ignore", "Organization Mode", "Task Difficulty", "Verbal Expression", "Proximity" and "Influence"

Symetrical Representation of Variables (dimensions F1 and F2:70,49\%)

Total Behaviorproblem-1

Proximity-1

1

0.5

Task difficulty-2

Influence-2

$\checkmark$

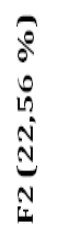

Motor engagement +-2

Ignore behavior-1

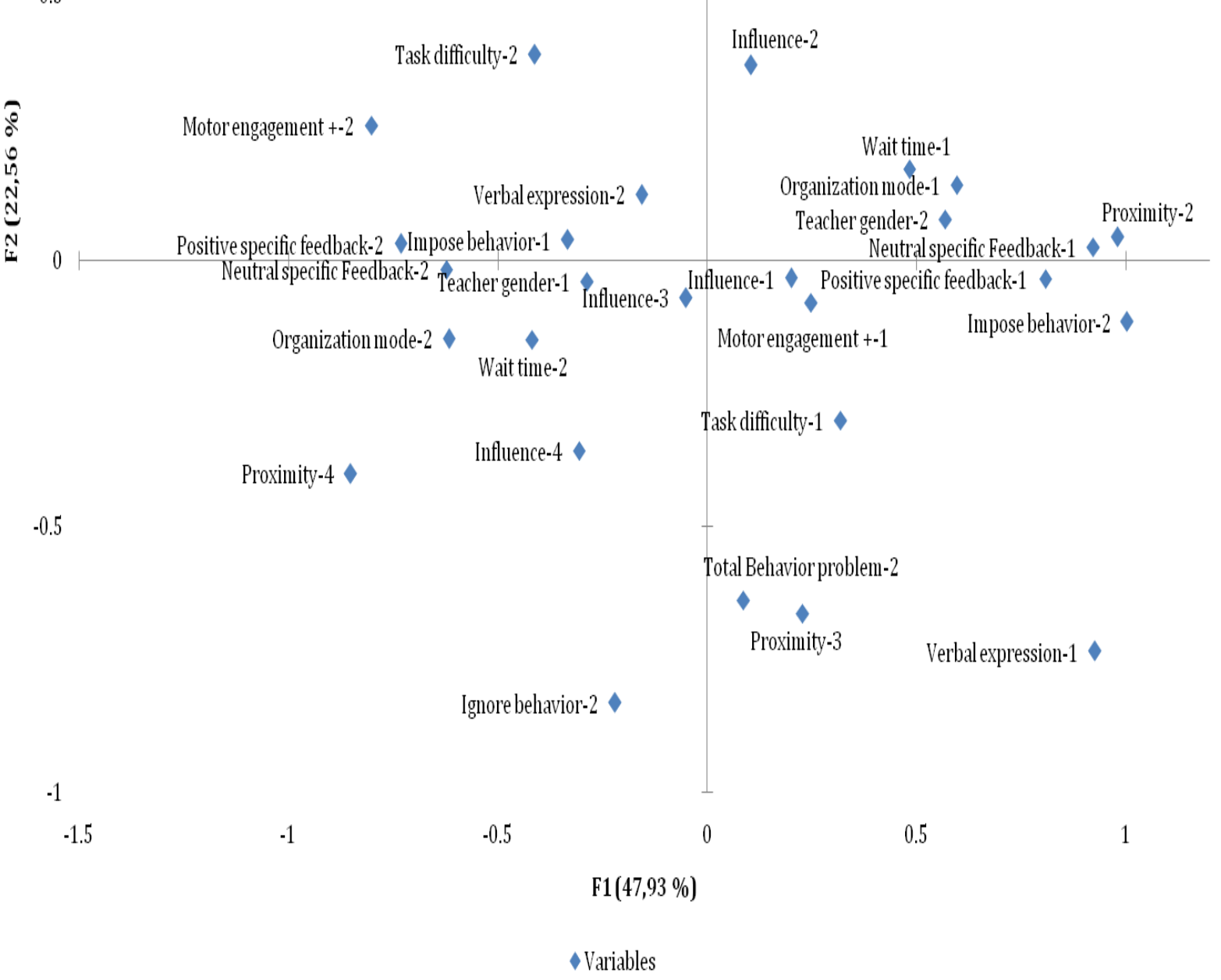




\section{Discussion}

This study's findings confirm the two hypotheses stated at the outset. Indeed, although the 565 participating students perceived favourably the interaction behaviour exhibited by the 25 graduating TTs, statistical analysis revealed that the HPE sessions that were being led by the TTs were characterized by a low degree of appropriate motor engagement of students, a high degree of waiting time and a relatively high frequency of undisciplined behaviours.

The findings reported in this study regarding involvement, atmosphere and the degree of disturbance that can be observed in HPE classrooms agree with those presented in the documentation available on novice teachers on one hand and types of learning situations on the other hand (Brunelle et al., 1996; Griffey \& Housner, 1991; Silverman et al., 1991). The first MCA also showed that "Motor engagement-2" is associated with the use of a command teaching style that has been considered appropriate to engage the students in a physical fitness setting (Mosston \& Ashworth, 2002). This element highlights the importance of the work done during the pre-impact phase, where TTs design tasks according to their perception of students' abilities, but also of changes to be made in progress when things do not go as planned.

In contrast, the technical-artistic, dual and cooperative activities are linked with a lower degree of motor engagement. This is mainly due to the fact that active supervision was less effective during these activities (Desbiens, 2002). For example, TTs had to supervise students on the trampoline (a high risk activity) or referee a game and therefore they could not easily supervise students waiting or moving elsewhere in the gymnasium. Organisation is a variable that strongly influences the LE. Clearly, "Organization mode- 1 " is associated with more episodes of deviance as well as "Influence-1,2".The discordant fact that "Organization mode-2" is associated with "Wait time-2 (Figure 3) might be explained by the fact that in our study, $68 \%$ of the sessions staged competitive situations involving cooperation and opposition. These activities are characterized by a high degree of waiting time given the physical and material constraints of which TTs had no control. Thus, a high latency does not automatically or necessarily relate to a problem organizing the session, but as we just mentioned, this might be due to aforementioned factors.

This study's findings also demonstrated that a deeper understanding of LE can be achieved through allowing TTs to build rapport with the students. In particular, the most interesting finding was that a high frequency of episodes of appropriate motor engagement and a reduced frequency of disruptive behaviours were associated with the combined presence of "Influence -4 " and "Proximity -4". In contrast, low (-2) and high levels(-3) of "Proximity" and very low (-1) to low (-2) "Influence" were associated with inefficient learning conditions as described by "Organization mode-1", "Motor engagement-1" and "Total BP-2". These observations are in line with those reported previously by Legault \& Lapointe (1999) and Wubbels et al., (1993) for regular classroom situations. 
Finally, the relationship revealed between the TTs' gender, motor engagement and inability to discipline is probably a specific effect related to our sample. It should be emphasised that male TTs led all fitness sessions while female TTs mostly led cooperative, dual or technical-artistic sessions. A sample built differently in terms of gender and types of sessions would probably have generated other relationships between the variables. Furthermore, it would be interesting to explore how female and male TTs respond to disruptive behaviours of students. Recent work by Desbiens et al., (2011) has shown that male TTs tend to use more permissive pedagogy while female TTs tend to use authoritarian and interactive pedagogy.

\section{Conclusion}

This study investigated LE using exiting analysis systems on the effectiveness of teaching in HPE while introducing the students' perspective which was absent in the original model developed by Martel et al., (1991). Also, this study proposed a new method to map the relationship between the variables to show their inter-relations. It is our view that, establishing and maintaining an environment conducive to learning in HPE is still a major challenge for graduating student teachers. Several skills are insufficiently mastered. These skills include: increasing the actual time spent on learning, reducing the frequency and intensity of disruptive behaviours, adopting efficient organisational modes, designing and implementing tasks tailored to students' abilities and adopting behaviours or attitudes to improve proximity. HPE programs are invited to revise their approaches of the learning experiences that are offered to HPE candidates during initial teacher training.

\section{Acknowledgements}

This research was made possible by a research grant from the Social Science and Humanities Research Council of Canada (2003-2006, no. 4102003 -1444).

\section{References}

Addinsoft (1995-2009). XLSTATS version 2009.6.01.http://www.xlstats.com.

Appache Software Foundation (Version 15) (2006). Statistical package for social sciences (SPSS).Chicago: Illinois.

Brophy, J.E. \& Good, T.L. (1974). The teacher's communicative competence: the first day of school. Theory Into Practice, 24(1): 63-70.

Brunelle, J., Brunelle, J.-P., Gagnon, J., Goyette, R., Martel, D., Marzouk, A. \& Spallanzani, C. (1993). Système d'observation des incidents disciplinaires (SOID) $\left(3^{\mathrm{e}}\right.$ version). Groupe de recherche en intervention en activité physique (GRIAP), 
Vol. 2, No. $1 \quad$ Desbiens et al.: Developing Effective Learning Environments...

département d'éducation physique, Faculté des sciences de l'éducation, Université Laval (Qc, Canada).

Brunelle, J., Spallanzani, C. Lord, M. \&t Petiot, B. (1983). Analyse du climat pédagogique par le biais des réactions des éducateurs physiques en situation d'enseignement. Canadian Association for Health Physical Education Recreation Journal, 49: 15-18.

Brunelle, J., Tousignant, M., Godbout, P. (avec la collaboration de Spallanzani, C., Brunelle, J-P., Martel, D., Trudel, P., Gagnon, J., Savard, C. \& Rami, A.) (1996). Le temps d'apprentissage. Sainte-Foy: GRIAP, département d'éducation physique, Université Laval.

Desbiens, J.-F. (2002). L'évaluation et la responsabilisation des élèves : ébauche d'une problématique sur le thème de la supervision active en enseignement de l'éducation physique. Brock Education, 12(1): 36-48.

Desbiens, J.-F., Turcotte, S., Spallanzani, C. Roy, M., Brunelle, J.-P., Tourigny, J.-S. \& Lanoue, S. (2008). Une analyse des comportements perturbateurs survenus durant des cours d'éducation physique et à la santé enseignés par des stagiaires. STAPS, 81: 73-88.

Desbiens, J-F., Turcotte, S., Spallanzani, C., Roy, M., Tourigny, J.-S., \& Lanoue, S. (2011). Comment des stagiaires en enseignement de l'éducation physique et à la santé réagissent-ils face à l'indiscipline de leurs élèves? Science \& Motricité, 73: 39-54.

Desbois, D. (2008). L'analyse des correspondances multiples « à la hollandaise»: introduction à l'analyse d'homogénéité. Revue Modulad, 38: 194-244.

Dumas, D. (2009). Perceptions des comportements interpersonnels d'enseignants et d'enseignantes d'éducation physique et à la santé par des élèves du secondaire. Mémoire de maîtrise non publié. Faculté d'éducation physique et sportive. Sherbrooke : Université de Sherbrooke.

Escofier, B. \& Pagès, J. (1998). Analyses factorielles simples et multiples (3ème éd.). Paris: Dunod.

Fortin, M.-F., Côté, J. \& Filion, F. (2006). Fondements et étapes du processus de recherche. Montréal :Chenelièreéducation.

Fraser, B. (2001). Twenty thousand hours: editor's introduction. Learning Environment Research, 4: 1-5.

Griffey, D.C. \& Housner, L. D. (1991). Differences between experienced and inexperienced teachers' planning decisions, interactions, student engagement, and instructional climate. Research Quarterly for Exercise and Sport, 62(2): 196204.

Legault, F. \& Lapointe, J. (1999). Version francophone du Questionnaire for Teacher Interaction en contexte québécois. Mesure et évaluation en éducation, 22(2-3): 119

Martel, D., Brunelle, J. \& Spallanzani, C. (1991). La détermination du degré d'implication des participants : un indice significatif du climat d'apprentissage. STAPS, 24: 37-50.

Ministère de l'éducation, du loisir et du sport (MELS). (2007). Programme de formation de l'école québécoise.Enseignement secondaire, deuxième cycle. Parcours de formation générale. Parcours de formation générale appliquée. Enseignement secondaire, deuxième cycle. Québec: Gouvernement du Québec.

Mosston, M. \& Ashworth, S. (2002). Teaching physical education ( $5^{\text {th }}$ ed.).New York: Benjamin Cummings.

Siedentop, D. (1994). Apprendre à enseigner l'éducation physique. (trad. et adap. par M. Tousignant, P. Boudreau et A. Fortier) ( $3^{\text {rd }}$ edition). Montréal : Gaëtan Morin. 
Silverman, S., Devillier, R. \& Ramirez, T. (1991). The validity of Academic learning time - physical education (ALT-PE) as a process measure of achievement. Research Quarterly for Exercise and Sport, 62(3): 319-325.

Turcotte, S., Desbiens, J.-F., Spallanzani, C., Roy, M., Brunelle, J.-P. \& Tourigny, J.S. (2008). Portrait des comportements perturbateurs adoptés par des élèves du niveau primaire en éducation physique et à la santé. eJRIEPS, 13: 57-77.

Ward, D. S. (1982). Student perception of the classroom learning environment in physical education. Journal of Teaching in Physical Education, (Autumn), 19-27.

Wubbels, T., Creton, H, Levy, J. \& Hooymayers, H. (1993). The model for interpersonal teacher behaviours. In T. Wubbelset J. Levy (eds), Do you know what you look like? Interpersonal Relationships in Education,13-18. London: Falmer Press. 
